\title{
Insight into the in-cloud formation of oxalate based on in situ measurement by single particle mass spectrometry
}

\author{
Guohua Zhang ${ }^{1}$, Qinhao Lin ${ }^{1,2}$, Long Peng ${ }^{1,2}$, Yuxiang Yang ${ }^{1,2}$, Yuzhen $\mathrm{Fu}^{1,2}$, Xinhui Bi ${ }^{1}$, Mei Li ${ }^{3}$, Duohong Chen ${ }^{4}$, \\ Jianxin Chen ${ }^{5}$, Zhang $\mathrm{Cai}^{6}$, Xinming Wang ${ }^{1}$, Ping'an Peng ${ }^{1}$, Guoying Sheng ${ }^{1}$, and Zhen Zhou ${ }^{3}$ \\ ${ }^{1}$ State Key Laboratory of Organic Geochemistry and Guangdong Key Laboratory of Environmental Resources Utilization and \\ Protection, Guangzhou Institute of Geochemistry, Chinese Academy of Sciences, Guangzhou 510640, PR China \\ ${ }^{2}$ University of Chinese Academy of Sciences, Beijing 100039, PR China \\ ${ }^{3}$ Institute of Mass Spectrometer and Atmospheric Environment, Jinan University, Guangzhou 510632, PR China \\ ${ }^{4}$ State Environmental Protection Key Laboratory of Regional Air Quality Monitoring, Guangdong Environmental \\ Monitoring Center, Guangzhou 510308, PR China \\ ${ }^{5}$ Shaoguan Environmental Monitoring Center, Shaoguan 512026, PR China \\ ${ }^{6}$ John and Willie Leone Family Department of Energy and Mineral Engineering, Pennsylvania State University, University \\ Park, PA 16802, USA
}

Correspondence to: Xinhui Bi (bixh@gig.ac.cn)

Received: 16 August 2017 - Discussion started: 18 August 2017

Revised: 17 October 2017 - Accepted: 18 October 2017 - Published: 22 November 2017

\begin{abstract}
While ground-based works suggest the significance of in-cloud production (or aqueous formation) to oxalate, direct evidence is rare. With the in situ measurements performed at a remote mountain site ( $1690 \mathrm{~m}$ above sea level) in southern China, we first reported the size-resolved mixing state of oxalate in the cloud droplet residual (cloud RES), the cloud interstitial (cloud INT), and ambient (cloud-free) particles by single particle mass spectrometry. The results support the growing evidence that in-cloud aqueous reactions promote the formation of oxalate, with $\sim 15 \%$ of the cloud RES and cloud INT particles containing oxalate in contrast to only $\sim 5 \%$ of the cloud-free particles. Furthermore, individual particle analysis provides unique insight into the formation of oxalate during in-cloud processing. Oxalate was predominantly ( $>70 \%$ in number) internally mixed with the aged biomass-burning particles, highlighting the impact of biomass burning on the formation of oxalate. In contrast, oxalate was underrepresented in aged elemental carbon particles, although they represented the largest fraction of the detected particles. It can be interpreted by the individual particle mixing state that the aged biomass-burning particles contained an abundance of organic components serving as precursors for oxalate. Through the analysis of the relationship between oxalate and organic acids $\left(-45\left[\mathrm{HCO}_{2}\right]^{-}\right.$,
\end{abstract}

$-59\left[\mathrm{CH}_{3} \mathrm{CO}_{2}\right]^{-},-71\left[\mathrm{C}_{2} \mathrm{H}_{3} \mathrm{CO}_{2}\right]^{-},-73\left[\mathrm{C}_{2} \mathrm{HO}_{3}\right]^{-}$), the results show that in-cloud aqueous reactions dramatically improved the conversion of organic acids to oxalate. The abundance of glyoxylate associated with the aged biomassburning particles is a controlling factor for the in-cloud production of oxalate. Since only limited information on oxalate is available in the free troposphere, the results also provide an important reference for future understanding of the abundance, evolution, and climate impacts of oxalate.

\section{Introduction}

In-cloud processing represents a large uncertainty in understanding the evolution and impact of secondary organic aerosols (SOA) on both environment and climate (Ervens et al., 2011; Ervens, 2015; Herrmann et al., 2015). Dicarboxylic acids significantly contribute to SOA, aerosol acidity, and hygroscopicity and thus play an important role in atmospheric chemistry and cloud condensation nuclei $(\mathrm{CCN}$; Ervens et al., 2011; Furukawa and Takahashi, 2011; Sorooshian et al., 2013). Oxalic acid is globally the most abundant dicarboxylic acid (Mochida et al., 2007; Ho et al., 2010; Kawamura and Bikkina, 2016), accounting for as high as $5 \%$ of 
water-soluble organic compounds downwind of the mainland China (Feng et al., 2012; Kawamura and Bikkina, 2016). In addition, oxalate has great impact on the solubility, photochemistry and bioavailability of transition metals in aerosols (Johnson and Meskhidze, 2013; Ito and Shi, 2016).

Although there are primary sources, such as combustion of coal/biomass and biogenic origins, oxalate is generally regarded as an oxidation product of malonate and glyoxylate, precursors of which include glyoxal, methylglyoxal, glycolic acid, pyruvic acid, acetic acid, and so on (Carlton et al., 2006; Myriokefalitakis et al., 2011; Kawamura and Bikkina, 2016). Large multifunctional compounds might also be important for the formation of oxalate (Carlton et al., 2007). The formation pathways mainly include photochemical oxidation followed by partitioning onto particulate-phase and in-cloud aqueous formation (Yu et al., 2005; Sullivan et al., 2007; Guo et al., 2016). The in-cloud aqueous pathway is generally proposed as the dominant pathway based on the similar pattern between both size distribution and concentration of oxalate and sulfate (Yu et al., 2005; Huang et al., 2006; Laongsri and Harrison, 2013). However, Zhou et al. (2015) argued that only $16 \%$ of oxalate could be attributed to in-cloud production despite its robust correlation with sulfate. Photochemical oxidation could account for $\sim 80 \%$ of oxalate in air mass influenced by biomass burning (Kundu et al., 2010). More direct evidences are needed to better evaluate the formation and behavior of oxalate during in-cloud processing. Through aircraft measurements, Sorooshian et al. (2006) observed higher concentration of oxalate in cloud droplet residual (cloud RES) particles, rather than in cloud-free atmospheric particles, over Ohio, USA. Similarly, elevated oxalate levels due to in-cloud processing were observed over coastal USA (Crahan et al., 2004; Sorooshian et al., 2010) and the Gulf of Mexico (Sorooshian et al., 2007a, b; Wonaschuetz et al., 2012). Recently, an aircraft measurement also provided an evidence on the important role of in-cloud production of oxalate from the near surface to the lower free troposphere (i.e., $\sim 2 \mathrm{~km}$ ) over inland China (Zhang et al., 2016). All of these in situ observations were based on bulk particles analysis and thus might miss some valuable information on the mixing state of oxalate, which is demonstrated to be significant for evaluating the life time and environmental impact of oxalate (Sullivan et al., 2007; Zhou et al., 2015). Information on oxalate in the atmosphere associated with cloud formation is still rare, far from enough for thoroughly understanding its distribution, sources, formation, evolution, and environmental impact (Kawamura et al., 2013; Meng et al., 2013, 2014).

Single particle mass spectrometry (SPMS) has been commonly applied to obtain mixing state of individual oxalatecontaining particles (Sullivan et al., 2007). Based on SPMS, oxalate was found to be extensively internally mixed with sulfate in the Arctic boundary layer (Hara et al., 2002). Similarly, the relative contributions of in-cloud processing, heterogeneous reactions, and biomass burning to oxalate in Shanghai were investigated (Yang et al., 2009). Sullivan et al. (2007) demonstrated the significant contribution of photochemical formation to oxalate followed by partitioning onto the dust and sea-salt particles. Zhou et al. (2015) proposed that oxalate was readily photodegraded in a form of oxalateFe complex in Hong Kong. However, such studies have not been conducted to investigate the in-cloud formation of oxalate. Investigation on the single particle mixing state of cloud/fog RES and interstitial (cloud INT) particles would provide unique insight into the formation and aging processes of aerosol compositions (Pratt et al., 2010; Li et al., 2011b; Zhang et al., 2012; Bi et al., 2016).

To better understand the in-cloud aqueous formation of oxalate, we investigated individual oxalate-containing particles at a high-altitude mountain site, representative of the free troposphere in southern China. Using a single particle aerosol mass spectrometer (SPAMS), the size-resolved mixing state of cloud-free, cloud RES, and cloud INT oxalate-containing particles were investigated. This paper reports data supporting the in-cloud production of oxalate and also discusses the influence of mixing state.

\section{Methods}

\subsection{Field measurement description}

Measurements of the cloud-free, cloud RES, and cloud INT particles were performed at the Nanling national background site $\left(24^{\circ} 41^{\prime} 56^{\prime \prime} \mathrm{N}, 112^{\circ} 53^{\prime} 56^{\prime \prime} \mathrm{E} ; 1690 \mathrm{~m}\right.$ a.s.1.) in southern China during 16-26 January 2016. Air masses from the southwestern continental and marine areas dominated over the sampling period, bringing relatively warmer and wetter air masses that benefited cloud formation (Lin et al., 2017), based on the back-trajectory analysis (HYSPLIT 4.9, available at http://ready.arl.noaa.gov/HYSPLIT.php) by Air Resources Lab (Stein et al., 2015). The air masses from northern areas, associated with cool dry airstreams, arrived during 18 and 23-24 January and resulted in a decrease in both temperature and relative humidity. Cloud events were characterized by a sudden drop in visibility (to $<5 \mathrm{~km}$ ) and a sharp increase in relative humidity (>95\%; Lin et al., 2017). In this study, three long-lasting (more than $12 \mathrm{~h}$ ) cloud events (Fig. 1), noted as cloud I, cloud II, and cloud III, were identified. The visibility were generally lower than $1 \mathrm{~km}$ during the cloud events.

Aerosols were introduced into the instruments through two parallel sampling inlets. The first one was a ground-based counterflow virtual impactor (GCVI; model 1205, Brechtel Mfg. Inc., USA), applied to obtain the cloud RES particles from the cloud droplets larger than $8 \mu \mathrm{m}$. The GCVI employed a compact wind tunnel upstream of the CVI inlet (model 1204) to accelerate cloud droplets in the CVI inlet tip (Shingler et al., 2012). Upstream of the CVI sampling tip, only droplets exceeding a certain controllable size (or cut size, set as $8 \mu \mathrm{m}$ in the present study) could pass through the 

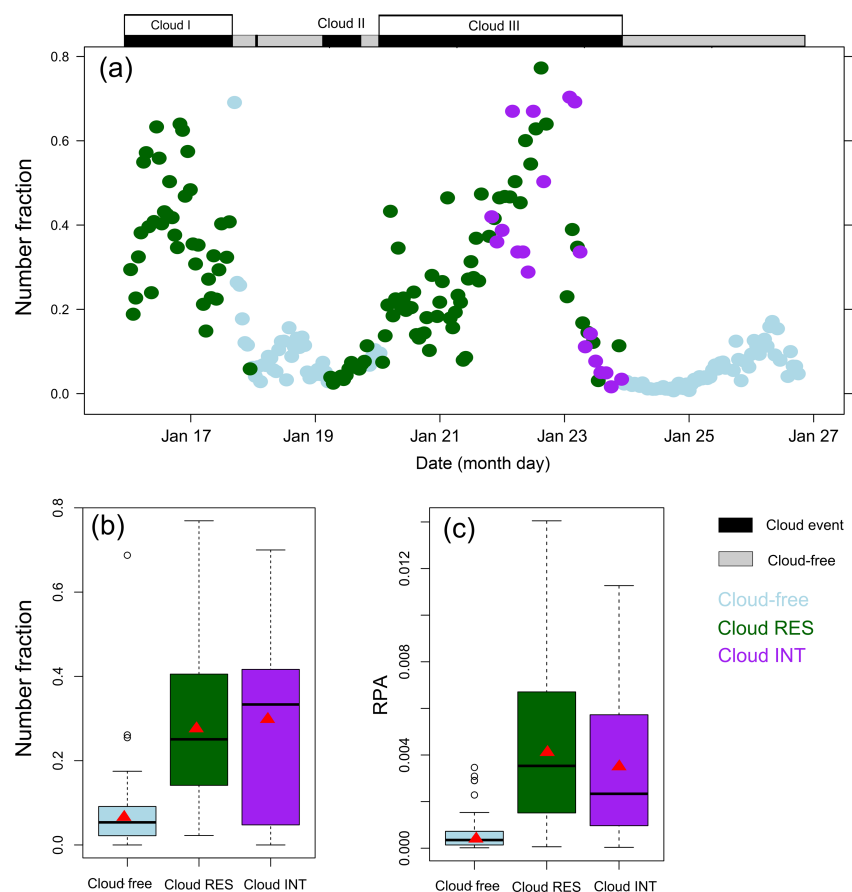

Figure 1. (a) Temporal variation (in 1-hour resolution) of number fractions (Nfs) of the oxalate-containing particles, box-andwhisker plots of (b) the Nfs of oxalate-containing particles as shown in (a), and (c) the relative peak area (RPA) of oxalate, separated for the cloud-free, cloud RES, and cloud INT particles. In a box-andwhisker plot, the lower, median, and upper line of the box denote the 25,50 , and 75 percentiles, respectively; the lower and upper edges of the whisker denote the 10 and 90 percentiles, respectively. Red triangles refer to the arithmetical mean values of the Nfs and RPAs shown in panels (b) and (c).

counterflow and enter the evaporation chamber (with an air flow temperature at $40^{\circ} \mathrm{C}$ ), where the droplets were dried, leaving the cloud RES particles that are capable of acting as CCN. A $15 \mathrm{~L} \mathrm{~min}^{-1}$ sample flow was provided to the downstream instruments. The enhancement factor for particles concentration collected by GCVI was 5.25, corresponding to the designation of the CVI. The detailed characterization and validation of the CVI sampling efficiency could be found elsewhere (Shingler et al., 2012). The flow rates of the whole GCVI system were validated before measurements and were also automatically monitored throughout the operation. A test on the cloud-free air showed that the average particles number concentration sampled by the GCVI was $\sim 1 \mathrm{~cm}^{-3}$, in contrast to $\sim 2000 \mathrm{~cm}^{-3}$ in ambient air. The testing demonstrates that the influence of background particles on the collection of the cloud RES particles could be negligible, further validating the performance of the GCVI. In the present study, the average number concentration of the cloud RES particles sampled during the cloud events was $\sim 250 \mathrm{~cm}^{-3}$ (Lin et al., 2017). The other one was an ambient
$\left(\mathrm{PM}_{2.5}\right)$ sampling inlet that was used to deliver cloud-free or cloud INT particles.

A SPAMS (Hexin Analytical Instrument Co., Ltd., Guangzhou, China), an Aethalometer (AE-33, Magee Scientific Inc.), and a scanning mobility particle sizer (SMPS; MSP Cooperation) were conducted to characterize the physical and chemical properties of the sampled particles. During cloud I and cloud II, the instruments were connected downstream the GCVI. During cloud III, cloud RES, and cloud INT particles were alternately sampled with an interval of $\sim 1 \mathrm{~h}$. During the cloud-free periods, these instruments were connected to the ambient inlet in order to measure the cloudfree particles. The presented results focused on the chemical composition and mixing state of the oxalate-containing particles detected by the SPAMS. Therefore, details for other instruments were not provided herein.

\subsection{Detection and classification of oxalate-containing particles}

The vacuum aerodynamic diameter $\left(d_{\mathrm{va}}\right)$ and mass spectral information for individual particles could be obtained by the SPAMS (Li et al., 2011a). A brief description on performance of the SPAMS can be found in the Supplement. Assuming Poisson distribution, standard errors for the number fraction (Nf) of particles were estimated (Pratt et al., 2010), since the particles were randomly detected by the SPAMS. Oxalate-containing particles are identified as particles with the presence of ion peak at $m / z-89$ (Sullivan and Prather, 2007; Zauscher et al., 2013). Approximate 6000 particles were identified as oxalate-containing particles, accounting for $8.1 \pm 0.1 \%$ of the total detected particles in the size range of $100-1600 \mathrm{~nm}$. The number-based mass spectra for these oxalate-containing particles is shown in Fig. S1 in the Supplement. They were clustered by a neural network algorithm based on the adaptive resonance theory (ART-2a), based on the presence and intensity of ion peaks (Song et al., 1999). Eight single particle types with distinct mass spectral characteristics (Fig. S2) were obtained for further analysis. More detail information on all the observed particle types could be found elsewhere (Lin et al., 2017).

\section{Results and discussion}

\subsection{Direct observational evidence for in-cloud production of oxalate}

The Nfs of the oxalate-containing particles relative to all the detected cloud-free, cloud RES, and cloud INT particles were $5.0 \pm 0.1,14.4 \pm 0.2$, and $13.4 \pm 1.1 \%$, respectively (Table 1 ). The Nfs of the oxalate-containing particles varied from near zero in the cloud-free particles to $\sim 80 \%$ in the cloud RES or cloud INT particles (Fig. 1). Consistently, the average relative peak area (RPA) of oxalate in the cloud RES and cloud INT particles suppressed by a factor 
of $\sim 8$ that in the cloud-free particles. Defined as fractional peak area of each $m / z$ relative to the sum of peak areas in a mass spectrum, RPA could represent the relative amount of a specie on a particle (Jeong et al., 2011; Healy et al., 2013). At ground level, oxalate was found in $\sim 3 \%$ of total particles in Shanghai (Yang et al., 2009) and the PRD region (Cheng et al., 2017), respectively. Relatively higher fraction of oxalate-containing particles in this study might reflect the importance of atmospheric ageing during long-range transport for the formation of oxalate at the high mountain site of southern China.

Analogous Nfs of the oxalate-containing particles in the cloud RES and cloud INT particles suggest the similar formation mechanism of oxalate in cloud droplets and interstitial particles, although Dall'Osto et al. (2009) indicated that difference might exist for secondary compounds formation between fog droplets and INT particles. The Nfs of the oxalate-containing particles in the cloud-free, cloud RES, and cloud INT particles versus $d_{\mathrm{va}}$ are displayed in Fig. 2. Oxalate-containing particles had higher Nfs in the cloudfree particles with $d_{\mathrm{va}}<0.3 \mu \mathrm{m}$, indicative of primary emission or photochemical production followed by condensation (Zauscher et al., 2013). This peak is most likely attributed to the photochemical production, since these smaller particles $(0.1-0.3 \mu \mathrm{m})$ were extensively (nearly $100 \%$ ) internally mixed with secondary species, such as sulfate and nitrate. In contrast, the Nfs of the oxalate-containing particles in the cloud RES and cloud INT particles increased with increasing $d_{\text {va }}$, showing a distinctly different pattern. It indicates that incloud aqueous reactions grow the cloud RES and cloud INT oxalate-containing particles with addition of secondary compositions (Schroder et al., 2015). It is further supported by the unscaled number size distribution of the cloud-free, cloud RES, and cloud INT oxalate-containing particles (Fig. S3), with $d_{\mathrm{va}}$ peaking at around $0.5,0.8$, and $0.7 \mu \mathrm{m}$, respectively.

It is further shown that the enhanced Nfs of the oxalatecontaining particles was not likely due to the influence of air mass. Firstly, the Nfs of the cloud-free oxalate-containing particles were generally low $(<10 \%)$ over the sampling period (Figs. 1 and S4), reflecting a background level of oxalate. Secondly, the Nfs and the RPAs of the cloud RES oxalate-containing particles exclusively sharply increased when RH was larger than $95 \%$ (Fig. S4). Significant enrichment of oxalate in the cloud RES particles demonstrates the importance of in-cloud aqueous reactions in the formation of oxalate (Sorooshian et al., 2006). Overall, these results provide direct evidences that the in-cloud aqueous processing is the dominant mechanism for oxalate in this study. More details on the formation mechanism and the dominant influence factors are discussed in the following text.

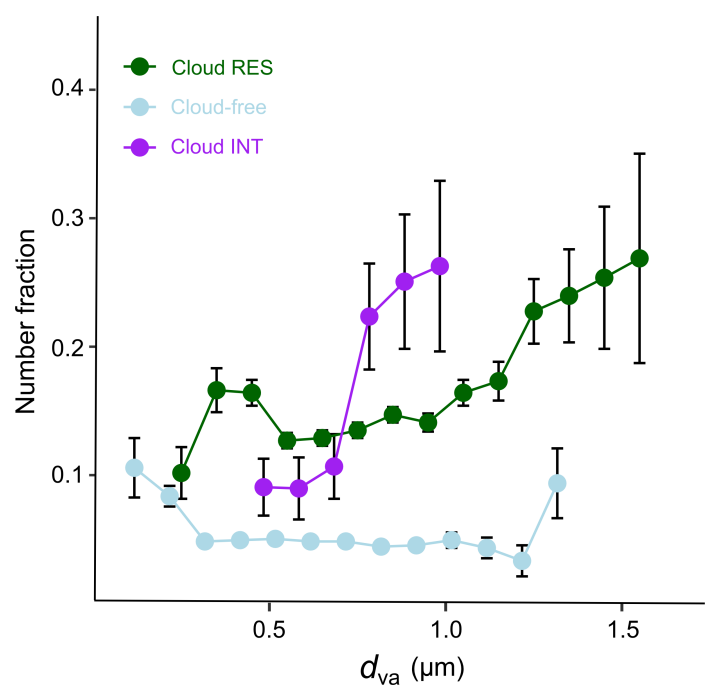

Figure 2. Size-dependent Nfs of oxalate-containing particles relative to all the detected cloud-free, cloud RES, and cloud INT particles.

\subsection{Predominant contribution of biomass and biofuel burning to oxalate}

Number fractions of the major ion peaks associated with the oxalate-containing particles were compared to those with all the detected particles, as shown in Fig. 3. Detailed information on the $\mathrm{Nfs}$ of all the detected ion peaks in the oxalate-containing particles could be found in Fig. S1. Potassium, with intense peak (peak area $>1000$ ) at $m / z 39 \mathrm{Da}$, was ubiquitously $(\sim 90 \%)$ associated with the oxalate-containing particles. It is attributed to highly sensitive of potassium to the desorption laser in the SPAMS, although $\mathrm{m} / z 39 \mathrm{Da}$ may also be appointed to $39\left[\mathrm{C}_{3} \mathrm{H}_{3}\right]^{+}$(Silva et al., 1999). Sulfate $\left(-97\left[\mathrm{HSO}_{4}\right]^{-}, 96 \%\right)$ and nitrate $\left(-62\left[\mathrm{HNO}_{3}\right]^{-}\right.$, $88 \%$ ) were the dominant secondary inorganic species associated with the oxalate-containing particles. Other major ion peaks were ammonium $\left(18\left[\mathrm{NH}_{4}\right]^{+}, 47 \%\right)$, organic nitrogen $\left(-26[\mathrm{CN}]^{-}, 76 \%\right)$, and oxidized organics (i.e., $m / z-45$, $-59,-71$, and -73 ) with the Nfs ranging from 17 to $57 \%$. These organics were most likely assigned to be formate at $m / z-45\left[\mathrm{HCO}_{2}\right]^{-}$, acetate at $\mathrm{m} / z-59\left[\mathrm{CH}_{3} \mathrm{CO}_{2}\right]^{-}$, methylglyoxal or acrylate at $m / z-71\left[\mathrm{C}_{2} \mathrm{H}_{3} \mathrm{CO}_{2}\right]^{-}$, and glyoxylate at $m / z-73\left[\mathrm{C}_{2} \mathrm{HO}_{3}\right]^{-}$(Zauscher et al., 2013). While might also be produced by levoglucosan, these ion peaks were most likely from secondary species in the present study. This is probably explained by the fact that their RPAs increased with increasing particle diameters (Fig. S5), consistent with that observed by Zauscher et al. (2013). These oxidized organics were commonly found in aged biomass-burning particles, regarded as organic acids (OAs). In addition, their Nfs tracked each other temporally in cloud-free particles (Table S1 in the Supplement), supporting their similar formation mechanisms, most likely formed through photochemical oxidation 
Table 1. The number and number fraction (Nf) of oxalate-containing particles in the all the detected cloud-free, cloud RES, and cloud INT particles.

\begin{tabular}{lrrr}
\hline & Cloud-free & Cloud RES & Cloud INT \\
\hline No. of all the detected particles & 48835 & 23616 & 1063 \\
No. of oxalate-containing particles & 2442 & 3410 & 142 \\
Nf of oxalate-containing particles & $5.0 \pm 0.1 \%$ & $14.4 \pm 0.2 \%$ & $13.4 \pm 1.1 \%$ \\
Nf of oxalate-containing particles classified & $76.3 \pm 1.8 \%$ & $70.0 \pm 1.4 \%$ & $71.8 \pm 7.1 \%$ \\
as aged biomass-burning particles & & & \\
\hline
\end{tabular}

followed by gas-to-particle partition (Zauscher et al., 2013). Other OAs with minor fractions $(\sim 10 \%)$ were also detected to be associated with the oxalate-containing particles, such as $m / z-87,-103$, and $-117 \mathrm{Da}$ due to pyruvate, malonate, and succinate, respectively. The extensive presence of potassium, OAs, and organic nitrogen reflects the substantial contribution of biomass burning to the observed oxalate (Pratt et al., 2010; Zauscher et al., 2013). The observed oxalatecontaining particles likely represented aged biomass-burning particles, associated with enhanced aliphatic acids (Paglione et al., 2014). Continuous evolution of primary organics to highly oxidized organics is widely observed for biomassburning particles (Cubison et al., 2011; Zhou et al., 2017). Significant correlations between these OAs were observed in aged biomass-burning particles (Zauscher et al., 2013) and also cloud water samples (Sorooshian et al., 2013). Hence, it is expected that the Nfs of these OAs were obviously higher in the oxalate-containing particles rather than those in the other detected particles (Fig. 3). In contrast to all the major ion peaks, ammonium had higher $\mathrm{Nf}$ in all particles rather than in the oxalate-containing particles. This is due to uneven distribution of ammonium among the different particle types of the oxalate-containing particles as discussed in the Supplement.

The contribution of biomass burning to the observed oxalate could also be reflected by the overwhelming presence of potassium-rich (K-rich) particles (Table 1 and Fig. S2), regarded as aged biomass-burning particles herein (Pratt et al., 2010; Bi et al., 2011; Zauscher et al., 2013). Following emission, biomass-burning particles become enriched in sulfate, nitrate, and OAs as ageing processes (Reid et al., 2005). It can be seen in Fig. 4 that $75.1 \pm 1.5 \%$ of oxalate was associated with the K-rich particles, although they only accounted for $36.0 \pm 0.3 \%$ of all the detected particles (Lin et al., 2017). Only $4.0 \pm 0.4 \%$ of oxalate was associated with the aged elemental carbon (EC) particles although they were the dominant fraction $(45.0 \pm 0.3 \%)$ of all the detected particles, reflecting an external mixing state. Enhancement of oxalate in the K-rich particles supports the favorable formation of oxalate in aged biomass-burning particles. Such a high fraction (i.e., $75.1 \pm 1.5 \%$ ) indicates a substantial contribution from secondary processing of biomass-burning particles in the present study, as discussed above. The result

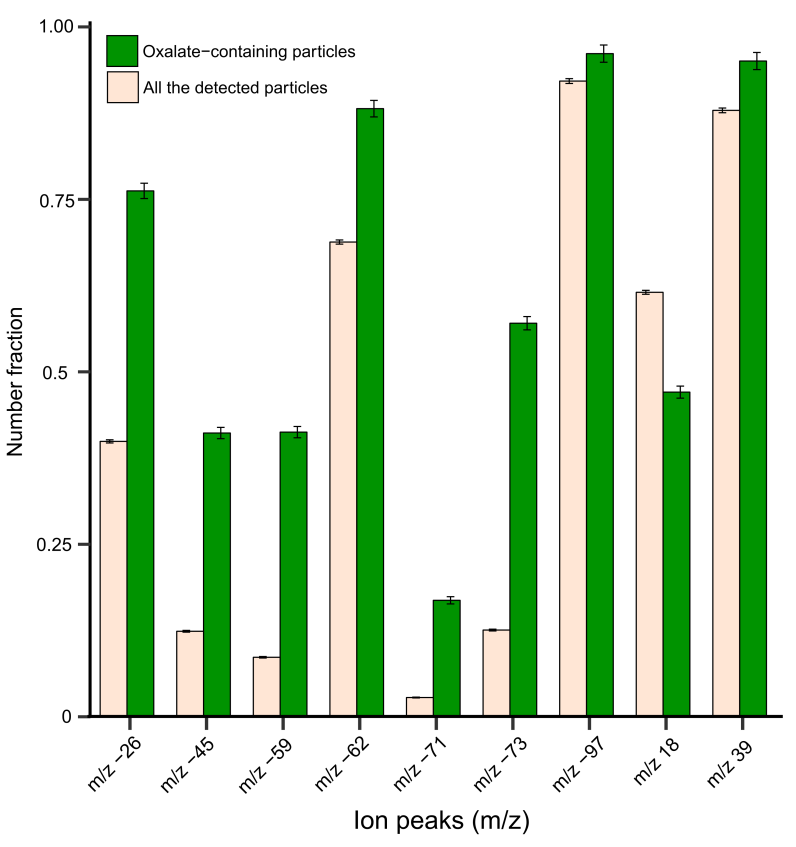

Figure 3. Number fractions of the major ion peaks in oxalatecontaining and all the detected particles.

is consistent with previous studies reporting that abundance of oxalate was substantially influenced by aged biomassburning particles (Gao et al., 2003; Yang et al., 2014; Zhou et al., 2015; Deshmukh et al., 2016). Primary emission from biomass burning contributes only a minor fraction to the observed oxalate in the atmosphere in China (Yang et al., 2009; Meng et al., 2013). Direct observation also supports the absence of oxalate in primary biomass-burning particles (Silva et al., 1999; Huo et al., 2016). A discussion on the preferential association of oxalate within Fe-rich and amine particles is provided in the Supplement.

\subsection{Pathway for in-cloud formation of oxalate in aged biomass-burning particles}

As shown in Table $1,>70 \%$ of oxalate by number was associated with the aged biomass-burning particles. It is also noted that $\sim 10 \%$ of the cloud-free K-rich particles contained oxalate, while the fraction increased to $>20 \%$ in the 


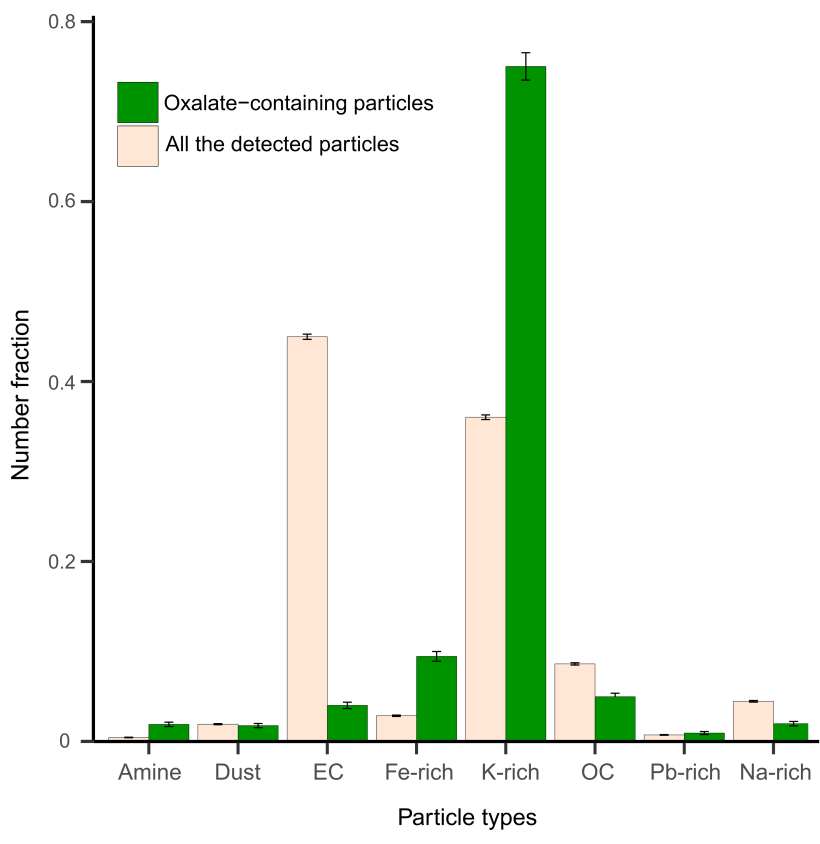

Figure 4. Number fractions of the single particle types for oxalatecontaining and all the detected particles.

cloud INT and cloud RES K-rich particles. This is not likely due to the preferential activation of the K-rich particles, since the Nfs of oxalate associated with the K-rich particles is similar (70-76\%) for the cloud-free, cloud RES, and cloud INT particles (Fig. S6). Therefore, the favorable formation of oxalate in the K-rich particles is most probably attributed to the enhanced organic precursors, as discussed in the following text.

The major OAs were predominantly associated with the oxalate-containing particles (Fig. 3) and also the K-rich particles (Table S2). Furthermore, significant correlations $(p<0.01)$ were found for the temporal profiles of the Nfs of the OAs and that of the oxalate-containing particles, in particular, for the cloud RES particles (Table S1). The highest correlation was found between the oxalate-containing particles and the glyoxylate-containing particles in the $\mathrm{Nf}$ and the RPA (Fig. 5). The correlations were significantly stronger for the cloud RES and cloud INT particles rather than for the cloud-free particles, suggesting the in-cloud production from glyoxylate as an important pathway for oxalate. It should further confirm the assignment of $m / z-73$ to glyoxylate, regarded as one of the primary intermediates contributing to formation of oxalate (Carlton et al., 2006; Myriokefalitakis et al., 2011). Miyazaki et al. (2009) suggested that secondary production of oxalate probably in aqueous phase is important via the oxidation of both longer-chain diacids and glyoxylate and would be enhanced in the biomass-burning-influenced particles. To our knowledge, it is the first report on the direct link and the internally mixing state between glyoxylate and oxalate during in-cloud processing with high time res-
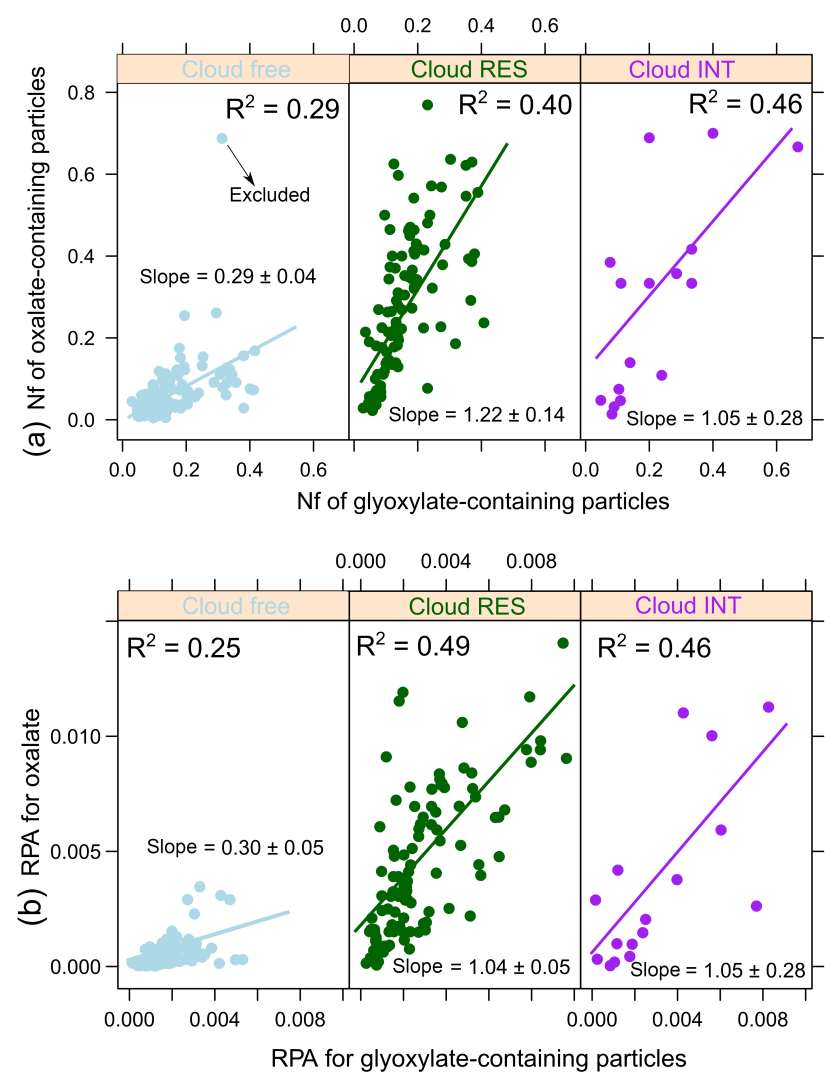

Figure 5. Simple linear regression (with least-square method) between (a) the Nfs and (b) the RPAs of the oxalate-containing and glyoxylate-containing particles, separated for the cloud-free $(N=109)$, cloud RES $(N=107)$, and cloud INT $(N=16)$ particles.

olution. Additionally, the linear regression slopes between glyoxylate and oxalate for the cloud RES and cloud INT particles were also higher than that for the cloud-free particles (Fig. 5), which also supports the more effective production of oxalate in cloud.

We further analyzed the relative fraction of the peaks areas of oxalate, glyoxylate, and OAs in the oxalate-containing particles during the cloud-free periods and cloud events (Fig. 6). It can be seen that the dots distribute close to the OAs during cloud-free periods, whereas they distribute towards oxalate during cloud events. This distribution indicates that the OAs were the dominant composition relative to oxalate and glyoxylate in the cloud-free oxalate-containing particles, whereas oxalate became more important in the cloud RES and cloud INT oxalate-containing particles. The different pattern is attributable to the conversion of some OAs to oxalate as a result of in-cloud aqueous reactions. It is also supported by the variations of the Nfs of the major OAs in the cloud-free, cloud RES, and cloud INT particles, respectively (Fig. S7). A substantial decrease $(\sim 50 \%$ on average) is found for the Nfs of the OAs associated with the oxalate-containing particles, from the cloud-free particles to 
(a) Cloud-free oxalate-containing particles

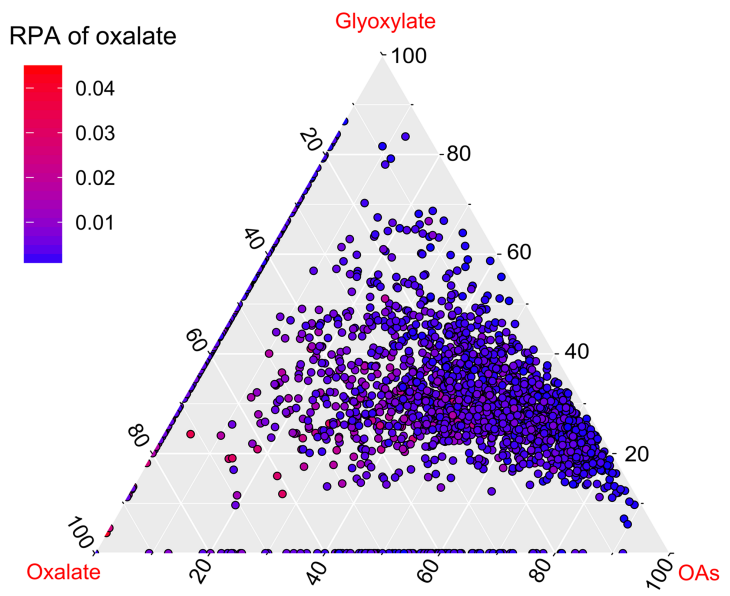

(b) Cloud RES and INT oxalate-containing particles Glyoxylate

100

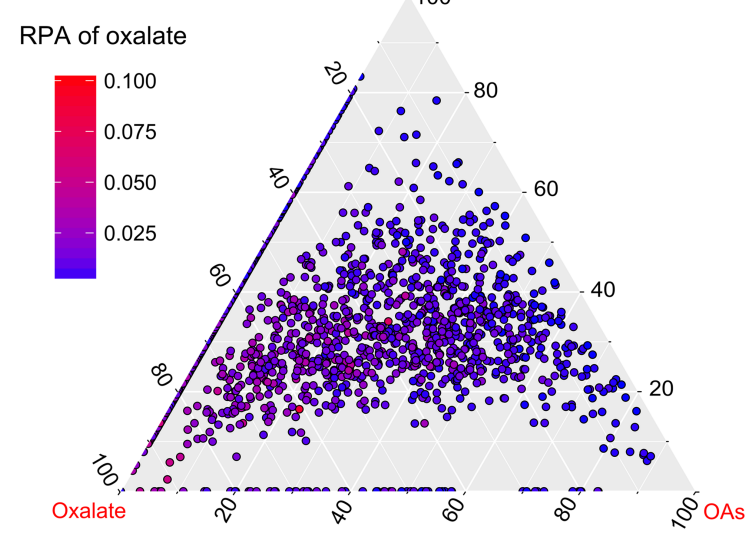

Figure 6. The relative distributions of the peak areas of oxalate, glyoxylate, and the OAs for (a) the individual cloud-free and (b) the cloud RES and cloud INT oxalate-containing particles. The peak areas of the OAs were summed from those of the individual OAs. The coloration indicates the RPA of oxalate.

the cloud RES or cloud INT particles. However, the Nfs of the OAs in all the detected particles did not show an obvious decrease. The conversion of the OAs to oxalate during incloud processing is consistent with the observation that oxalate increased as the droplets evaporated, while acetate, glyoxylate, and malonate decreased (Sorooshian et al., 2007b).

Most of previous studies considered that glyoxylate is dominantly produced from aqueous oxidation of glyoxal or glycolic acid, depending on volatile organic compounds (Ervens et al., 2004; Sorooshian et al., 2006, 2007b). Aqueousphase reactions promote the production of oxalate through increasing the partitioning of gases into droplets (Sorooshian et al., 2007a). Assuming that the in-cloud formation of oxalate was dominantly contributed from the volatile organic compounds, glyoxylate and oxalate would be evenly formed

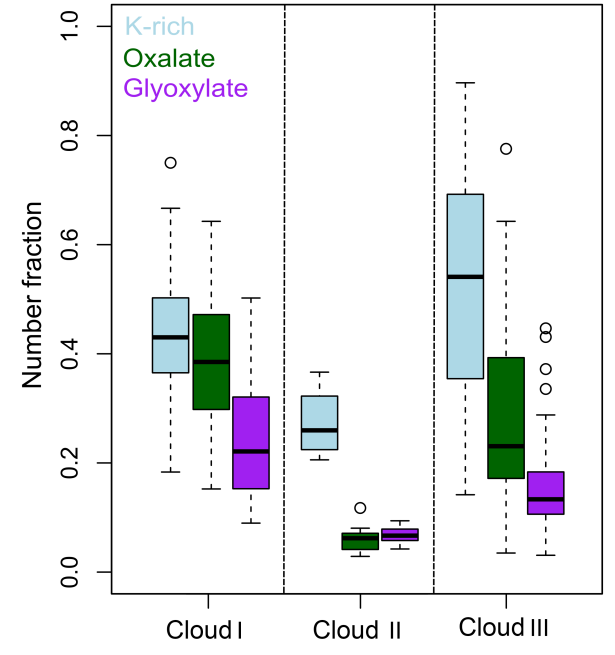

Figure 7. Box-and-whisker plots of the variations of Nfs for the Krich, oxalate-containing, and glyoxylate-containing particles during the cloud events.

in all the particle types, which is inconsistent with our observation that they were predominantly associated with the aged biomass-burning particles (Fig. 3). It indicates that a certain amount of glyoxylate should be directly produced in cloud from the organics formed before the cloud events and associated with aged biomass-burning particles. Aqueous-phase processing of biomass-burning emissions was demonstrated to be a substantial contributor to the SOA (Gilardoni et al., 2016). Existing models typically treat cloud droplets as a well-mixed bulk aqueous phase (McNeill, 2015) and initialize the particle composition as pure ammonium sulfate (Ervens et al., 2004; Sorooshian et al., 2006). Our results suggest that a particle-type-based model with detailed chemical mixing state is required for further understanding on the modification of particle properties by in-cloud processing in the troposphere.

\subsection{Case study for the influence of air mass on the formation of oxalate}

Cloud II represented a relatively more polluted condition, with $\mathrm{PM}_{2.5}$ around $200 \mathrm{ng} \mathrm{m}^{-3}, \sim 4$ times those during cloud I and III. Air mass analysis showed that cloud II was strongly influenced by northeastern air mass, contrasting to the southwestern air mass during cloud I and III (Lin et al., 2017). Figure 7 compares the respective Nfs of the K-rich, oxalatecontaining, and glyoxylate-containing particles during the three cloud events. It is found that the $\mathrm{Nf}$ of the oxalatecontaining particles was substantially lower during cloud II. Similarly, the Nf of the glyoxylate-containing particles during cloud II was significantly lower, which is also in accordance to other oxidized organics (Table S3). The K-rich particles were found to contribute $\sim 25 \%$ of the cloud RES particles during cloud II, significantly lower than its con- 
tribution $(\sim 50 \%)$ during cloud I and III. Regarding the higher correlation between the Nfs of oxalate-containing and glyoxylate-containing particles, relative to that between the oxalate-containing and K-rich particles (Table S1), the result might indicate that in-cloud production of oxalate on the aged biomass-burning particles is dominantly controlled by the glyoxylate. The aged biomass-burning particles from northeastern air mass contained less amount of oxidized organics for the formation of oxalate. Cloud water content plays an important role in both the formation and scavenging of water-soluble ions (Zhou et al., 2009; Wang et al., 2012), and thus might contribute to the lower fraction of oxalate during cloud II. Model simulation indicates that the formation of oxalate is as a function of cloud processing time and droplet sizes, which directly links to the cloud water content (Sorooshian et al., 2013). With visibility as an indicator (Table S3), the lowest cloud water content is expected during cloud II. However, non-significant correlation was found between the $\mathrm{Nf}$ of the oxalate-containing particles and visibility. Short cloud processing time could not be the main reason for the lower $\mathrm{Nf}$ of oxalate-containing particles during cloud II. As can be seen in Fig. 1, the Nf of oxalate-containing particles increased to $20 \%$ within several hours during clouds I and III.

\section{Conclusions}

Individual particle mixing state of oxalate in the cloud-free, cloud RES, and cloud INT particles obtained at a remote mountain site allows for the investigation of formation and evolution of oxalate. Our results show significant enhancement of oxalate in the cloud RES and cloud INT particles, rather than in the cloud-free particles, providing first direct observational evidence for the in-cloud production of oxalate in the troposphere in China and strengthening the growing evidence that aqueous-phase chemistry is the predominant formation mechanism for oxalate. The influence of biomass burning on the formation of oxalate was also highlighted, with predominant fraction $(>70 \%)$ of oxalate internally mixed with the aged biomass-burning particles. Formation of oxalate is highly dependent on the abundance of organic acids strongly associated with the aged biomassburning particles, with glyoxylate as an important intermediate. In-cloud chemically segregated production of oxalate would lead to a substantial change of the biomass-burning particles after cloud evaporation, different from other particle types (e.g., aged EC particles externally mixed with oxalate). This would have important implication for accurate modeling the formation and influence of oxalate in the atmosphere.

Data availability. Data are available on request from Xinhui Bi (bixh@gig.ac.cn).

\section{The Supplement related to this article is available online at https://doi.org/10.5194/acp-17-13891-2017- supplement.}

Competing interests. The authors declare that they have no conflict of interest.

Special issue statement. This article is part of the special issue "Regional transport and transformation of air pollution in eastern China". It is not associated with a conference.

Acknowledgements. This work was supported by the National Key Research and Development Program of China (2017YFC0210104), the National Nature Science Foundation of China (No. 91544101 and 41775124), the Foundation for Leading Talents of the Guangdong Province Government, and the State Key Laboratory of Organic Geochemistry (SKLOGA201603A and SKLOGC201604). This is contribution no. IS-2469 from GIGCAS.

Edited by: Armin Sorooshian

Reviewed by: two anonymous referees

\section{References}

Bi, X. H., Zhang, G. H., Li, L., Wang, X. M., Li, M., Sheng, G. Y., Fu, J. M., and Zhou, Z.: Mixing state of biomass burning particles by single particle aerosol mass spectrometer in the urban area of PRD, China, Atmos. Environ., 45, 3447-3453, https://doi.org/10.1016/j.atmosenv.2011.03.034, 2011.

Bi, X. H., Lin, Q. H., Peng, L., Zhang, G. H., Wang, X. M., Brechtel, F. J., Chen, D. H., Li, M., Peng, P. A., Sheng, G. Y., and Zhou, Z.: In situ detection of the chemistry of individual fog droplet residues in the Pearl River Delta region, China, J. Geophys. Res.-Atmos., 121, 9105-9116, https://doi.org/10.1002/2016JD024886, 2016.

Carlton, A. G., Turpin, B. J., Lim, H. J., Altieri, K. E., and Seitzinger, S.: Link between isoprene and secondary organic aerosol (SOA): Pyruvic acid oxidation yields low volatility organic acids in clouds, Geophys. Res. Lett., 33, L06822, https://doi.org/10.1029/2005gl025374, 2006.

Carlton, A. G., Turpin, B. J., Altieri, K. E., Seitzinger, S., Reff, A., Lim, H. J., and Ervens, B.: Atmospheric oxalic acid and SOA production from glyoxal: Results of aqueous photooxidation experiments, Atmos. Environ., 41, 7588-7602, https://doi.org/10.1016/j.atmosenv.2007.05.035, 2007.

Cheng, C., Li, M., Chan, C. K., Tong, H., Chen, C., Chen, D., Wu, D., Li, L., Wu, C., Cheng, P., Gao, W., Huang, Z., Li, X., Zhang, Z., Fu, Z., Bi, Y., and Zhou, Z.: Mixing state of oxalic acid containing particles in the rural area of Pearl River Delta, China: implications for the formation mechanism of oxalic acid, Atmos. Chem. Phys., 17, 9519-9533, https://doi.org/10.5194/acp17-9519-2017, 2017. 
Crahan, K. K., Hegg, D., Covert, D. S., and Jonsson, H.: An exploration of aqueous oxalic acid production in the coastal marine atmosphere, Atmos. Environ., 38, 3757-3764, 2004.

Cubison, M. J., Ortega, A. M., Hayes, P. L., Farmer, D. K., Day, D., Lechner, M. J., Brune, W. H., Apel, E., Diskin, G. S., Fisher, J. A., Fuelberg, H. E., Hecobian, A., Knapp, D. J., Mikoviny, T., Riemer, D., Sachse, G. W., Sessions, W., Weber, R. J., Weinheimer, A. J., Wisthaler, A., and Jimenez, J. L.: Effects of aging on organic aerosol from open biomass burning smoke in aircraft and laboratory studies, Atmos. Chem. Phys., 11, 12049-12064, https://doi.org/10.5194/acp-11-12049-2011, 2011.

Dall'Osto, M., Harrison, R. M., Coe, H., and Williams, P.: Realtime secondary aerosol formation during a fog event in London, Atmos. Chem. Phys., 9, 2459-2469, https://doi.org/10.5194/acp9-2459-2009, 2009.

Deshmukh, D. K., Kawamura, K., and Deb, M. K.: Dicarboxylic acids, $\omega$-oxocarboxylic acids, $\alpha$-dicarbonyls, WSOC, OC, EC, and inorganic ions in wintertime size-segregated aerosols from central India: Sources and formation processes, Chemosphere, 161, 27-42, https://doi.org/10.1016/j.chemosphere.2016.06.107, 2016.

Ervens, B.: Modeling the Processing of Aerosol and Trace Gases in Clouds and Fogs, Chem. Rev., 115, 4157-4198, https://doi.org/10.1021/cr5005887, 2015.

Ervens, B., Feingold, G., Frost, G. J., and Kreidenweis, S. M.: A modeling study of aqueous production of dicarboxylic acids: 1. Chemical pathways and speciated organic mass production, J. Geophys. Res.-Atmos., 109, 1265-1277, https://doi.org/10.1029/2003jd004387, 2004.

Ervens, B., Turpin, B. J., and Weber, R. J.: Secondary organic aerosol formation in cloud droplets and aqueous particles (aqSOA): a review of laboratory, field and model studies, Atmos. Chem. Phys., 11, 11069-11102, https://doi.org/10.5194/acp-1111069-2011, 2011

Feng, J. L., Guo, Z. G., Zhang, T. R., Yao, X. H., Chan, C. K., and Fang, M.: Source and formation of secondary particulate matter in $\mathrm{PM}_{2.5}$ in Asian continental outflow, J. Geophys. Res.-Atmos., 117, 812-819, https://doi.org/10.1029/2011jd016400, 2012.

Furukawa, T. and Takahashi, Y.: Oxalate metal complexes in aerosol particles: implications for the hygroscopicity of oxalatecontaining particles, Atmos. Chem. Phys., 11, 4289-4301, https://doi.org/10.5194/acp-11-4289-2011, 2011.

Gao, S., Hegg, D. A., Hobbs, P. V., Kirchstetter, T. W., Magi, B. I., and Sadilek, M.: Water-soluble organic components in aerosols associated with savanna fires in southern Africa: Identification, evolution, and distribution, J. Geophys. Res.-Atmos., 108, 471475, 2003

Gilardoni, S., Massoli, P., Paglione, M., Giulianelli, L., Carbone, C., Rinaldi, M., Decesari, S., Sandrini, S., Costabile, F., Gobbi, G. P., Pietrogrande, M. C., Visentin, M., Scotto, F., Fuzzi, S., and Facchini, M. C.: Direct observation of aqueous secondary organic aerosol from biomass-burning emissions, P. Natl. Acad. Sci. USA, 113, 10013-10018, 2016.

Guo, T. F., Li, K., Zhu, Y. J., Gao, H. W., and Yao, X. H.: Concentration and size distribution of particulate oxalate in marine and coastal atmospheres - Implication for the increased importance of oxalate in nanometer atmospheric particles, Atmos. Environ., 142, 19-31, 2016.
Hara, K., Osada, K., Matsunaga, K., Sakai, T., Iwasaka, Y., and Furuya, K.: Concentration trends and mixing states of particulate oxalate in Arctic boundary layer in winter/spring, J. Geophys. Res.-Atmos., 107, AAC 12-11-AAC 12-14, 2002.

Healy, R. M., Sciare, J., Poulain, L., Crippa, M., Wiedensohler, A., Prevot, A. S. H., Baltensperger, U., Sarda-Esteve, R., McGuire, M. L., Jeong, C. H., McGillicuddy, E., O’Connor, I. P., Sodeau, J. R., Evans, G. J., and Wenger, J. C.: Quantitative determination of carbonaceous particle mixing state in Paris using single-particle mass spectrometer and aerosol mass spectrometer measurements, Atmos. Chem. Phys., 13, 9479-9496, https://doi.org/10.5194/acp-13-9479-2013, 2013.

Herrmann, H., Schaefer, T., Tilgner, A., Styler, S. A., Weller, C., Teich, M., and Otto, T.: Tropospheric Aqueous-Phase Chemistry: Kinetics, Mechanisms, and Its Coupling to a Changing Gas Phase, Chem. Rev., 115, 4259-4334, https://doi.org/10.1021/cr500447k, 2015.

Ho, K. F., Lee, S. C., Ho, S. S. H., Kawamura, K., Tachibana, E., Cheng, Y., and Zhu, T.: Dicarboxylic acids, ketocarboxylic acids, alpha-dicarbonyls, fatty acids, and benzoic acid in urban aerosols collected during the 2006 Campaign of Air Quality Research in Beijing (CAREBeijing-2006), J. Geophys. Res.-Atmos., 115, D19312, https://doi.org/10.1029/2009JD013304, 2010.

Huang, X. F., Yu, J. Z., He, L. Y., and Yuan, Z. B.: Watersoluble organic carbon and oxalate in aerosols at a coastal urban site in China: Size distribution characteristics, sources, and formation mechanisms, J. Geophys. Res.-Atmos., 111, D22212, https://doi.org/10.1029/2006jd007408, 2006.

Huo, J., Lu, X., Wang, X., Chen, H., Ye, X., Gao, S., Gross, D. S., Chen, J., and Yang, X.: Online single particle analysis of chemical composition and mixing state of crop straw burning particles: from laboratory study to field measurement, Frontiers of Environmental Science \& Engineering, 10, 244-252, https://doi.org/10.1007/s11783-015-0768-z, 2016.

Ito, A. and Shi, Z.: Delivery of anthropogenic bioavailable iron from mineral dust and combustion aerosols to the ocean, Atmos. Chem. Phys., 16, 85-99, https://doi.org/10.5194/acp-16-852016, 2016.

Jeong, C. H., McGuire, M. L., Godri, K. J., Slowik, J. G., Rehbein, P. J. G., and Evans, G. J.: Quantification of aerosol chemical composition using continuous single particle measurements, Atmos. Chem. Phys., 11, 7027-7044, https://doi.org/10.5194/acp11-7027-2011, 2011.

Johnson, M. S. and Meskhidze, N.: Atmospheric dissolved iron deposition to the global oceans: effects of oxalate-promoted $\mathrm{Fe}$ dissolution, photochemical redox cycling, and dust mineralogy, Geosci. Model Dev., 6, 1137-1155, https://doi.org/10.5194/gmd6-1137-2013, 2013.

Kawamura, K. and Bikkina, S.: A review of dicarboxylic acids and related compounds in atmospheric aerosols: Molecular distributions, sources and transformation, Atmos. Res., 170, 140-160, 2016.

Kawamura, K., Tachibana, E., Okuzawa, K., Aggarwal, S. G., Kanaya, Y., and Wang, Z. F.: High abundances of water-soluble dicarboxylic acids, ketocarboxylic acids and alpha-dicarbonyls in the mountaintop aerosols over the North China Plain during wheat burning season, Atmos. Chem. Phys., 13, 8285-8302, 2013. 
Kundu, S., Kawamura, K., Andreae, T. W., Hoffer, A., and Andreae, M. O.: Molecular distributions of dicarboxylic acids, ketocarboxylic acids and a-dicarbonyls in biomass burning aerosols: implications for photochemical production and degradation in smoke layers, Atmos. Chem. Phys., 10, 2209-2225, https://doi.org/10.5194/acp-10-2209-2010, 2010.

Laongsri, B. and Harrison, R. M.: Atmospheric behaviour of particulate oxalate at UK urban background and rural sites, Atmos. Environ., 71, 319-326, 2013.

Li, L., Huang, Z. X., Dong, J. G., Li, M., Gao, W., Nian, H. Q., Fu, Z., Zhang, G. H., Bi, X. H., Cheng, P., and Zhou, Z.: Real time bipolar time-of-flight mass spectrometer for analyzing single aerosol particles, Intl. J. Mass. Spectrom., 303, 118-124, https://doi.org/10.1016/j.ijms.2011.01.017, 2011a.

Li, W. J., Li, P. R., Sun, G. D., Zhou, S. Z., Yuan, Q., and Wang, W. X.: Cloud residues and interstitial aerosols from non-precipitating clouds over an industrial and urban area in northern China, Atmos. Environ., 45, 2488-2495, https://doi.org/10.1016/j.atmosenv.2011.02.044, 2011 b.

Lin, Q., Zhang, G., Peng, L., Bi, X., Wang, X., Brechtel, F. J., Li, M., Chen, D., Peng, P., Sheng, G., and Zhou, Z.: In situ chemical composition measurement of individual cloud residue particles at a mountain site, southern China, Atmos. Chem. Phys., 17, 84738488, https://doi.org/10.5194/acp-17-8473-2017, 2017.

McNeill, V. F.: Aqueous Organic Chemistry in the Atmosphere: Sources and Chemical Processing of Organic Aerosols, Environ. Sci. Technol., 49, 1237-1244, https://doi.org/10.1021/es5043707, 2015.

Meng, J. J., Wang, G. H., Li, J. J., Cheng, C. L., and Cao, J. J.: Atmospheric oxalic acid and related secondary organic aerosols in Qinghai Lake, a continental background site in Tibet Plateau, Atmos. Environ., 79, 582-589, 2013.

Meng, J. J., Wang, G. H., Li, J. J., Cheng, C. L., Ren, Y. Q., Huang, Y., Cheng, Y. T., Cao, J. J., and Zhang, T.: Seasonal characteristics of oxalic acid and related SOA in the free troposphere of Mt. Hua, central China: Implications for sources and formation mechanisms, Sci. Total. Environ., 493, 1088-1097, 2014.

Miyazaki, Y., Aggarwal, S. G., Singh, K., Gupta, P. K., and Kawamura, K.: Dicarboxylic acids and water-soluble organic carbon in aerosols in New Delhi, India, in winter: Characteristics and formation processes, J. Geophys. Res.-Atmos., 114, D19206, https://doi.org/10.1029/2009JD011790, 2009.

Mochida, M., Umemoto, N., Kawamura, K., Lim, H. J., and Turpin, B. J.: Bimodal size distributions of various organic acids and fatty acids in the marine atmosphere: Influence of anthropogenic aerosols, Asian dusts, and sea spray off the coast of East Asia, J. Geophys. Res.-Atmos., 112, 229-238, 2007.

Myriokefalitakis, S., Tsigaridis, K., Mihalopoulos, N., Sciare, J., Nenes, A., Kawamura, K., Segers, A., and Kanakidou, M.: In-cloud oxalate formation in the global troposphere: a 3-D modeling study, Atmos. Chem. Phys., 11, 5761-5782, https://doi.org/10.5194/acp-11-5761-2011, 2011.

Paglione, M., Saarikoski, S., Carbone, S., Hillamo, R., Facchini, M. C., Finessi, E., Giulianelli, L., Carbone, C., Fuzzi, S., Moretti, F., Tagliavini, E., Swietlicki, E., Stenstrom, K. E., Prevot, A. S. H., Massoli, P., Canaragatna, M., Worsnop, D., and Decesari, S.: Primary and secondary biomass burning aerosols determined by proton nuclear magnetic resonance (H-1-NMR) spectroscopy during the 2008 EUCAARI campaign in the Po Valley (Italy), At- mos. Chem. Phys., 14, 5089-5110, https://doi.org/10.5194/acp14-5089-2014, 2014.

Pratt, K. A., Heymsfield, A. J., Twohy, C. H., Murphy, S. M., DeMott, P. J., Hudson, J. G., Subramanian, R., Wang, Z. E., Seinfeld, J. H., and Prather, K. A.: In Situ Chemical Characterization of Aged Biomass-Burning Aerosols Impacting Cold Wave Clouds, J. Atmos. Sci., 67, 2451-2468, https://doi.org/10.1175/2010JAS3330.1, 2010.

Reid, J. S., Koppmann, R., Eck, T. F., and Eleuterio, D. P.: A review of biomass burning emissions part II: intensive physical properties of biomass burning particles, Atmos. Chem. Phys., 5, 799825, 2005.

Schroder, J. C., Hanna, S. J., Modini, R. L., Corrigan, A. L., Kreidenwies, S. M., Macdonald, A. M., Noone, K. J., Russell, L. M., Leaitch, W. R., and Bertram, A. K.: Size-resolved observations of refractory black carbon particles in cloud droplets at a marine boundary layer site, Atmos. Chem. Phys., 15, 1367-1383, https://doi.org/10.5194/acp-15-1367-2015, 2015.

Shingler, T., Dey, S., Sorooshian, A., Brechtel, F. J., Wang, Z., Metcalf, A., Coggon, M., Mulmenstadt, J., Russell, L. M., Jonsson, H. H., and Seinfeld, J. H.: Characterisation and airborne deployment of a new counterflow virtual impactor inlet, Atmos. Meas. Tech., 5, 1259-1269, https://doi.org/10.5194/amt-5-1259-2012, 2012.

Silva, P. J., Liu, D. Y., Noble, C. A., and Prather, K. A.: Size and chemical characterization of individual particles resulting from biomass burning of local Southern California species, Environ. Sci. Technol., 33, 3068-3076, 1999.

Stein, A. F., Draxler, R. R, Rolph, G. D., Stunder, B. J. B., Cohen, M. D., and Ngan, F.: NOAA's HYSPLIT atmospheric transport and dispersion modeling system, B. Am. Meteorol. Soc., 96, 2059-2077, https://doi.org/10.1175/BAMS-D-14-00110.1, 2015

Song, X. H., Hopke, P. K., Fergenson, D. P., and Prather, K. A.: Classification of single particles analyzed by ATOFMS using an artificial neural network, ART-2A, Anal. Chem., 71, 860-865, 1999.

Sorooshian, A., Varutbangkul, V., Brechtel, F. J., Ervens, B., Feingold, G., Bahreini, R., Murphy, S. M., Holloway, J. S., Atlas, E. L., Buzorius, G., Jonsson, H., Flagan, R. C., and Seinfeld, J. H.: Oxalic acid in clear and cloudy atmospheres: Analysis of data from International Consortium for Atmospheric Research on Transport and Transformation 2004, J. Geophys. Res.-Atmos., 111, 23-45, https://doi.org/10.1029/2005jd006880, 2006.

Sorooshian, A., Lu, M. L., Brechtel, F. J., Jonsson, H., Feingold, G., Flagan, R. C., and Seinfeld, J. H.: On the source of organic acid aerosol layers above clouds, Environ. Sci. Technol., 41, 46474654, 2007a.

Sorooshian, A., Ng, N. L., Chan, A. W. H., Feingold, G., Flagan, R. C., and Seinfeld, J. H.: Particulate organic acids and overall water-soluble aerosol composition measurements from the 2006 Gulf of Mexico Atmospheric Composition and Climate Study (GoMACCS), J. Geophys. Res.-Atmos., 112, 125-138, https://doi.org/10.1029/2007jd008537, 2007b.

Sorooshian, A., Murphy, S. M., Hersey, S., Bahreini, R., Jonsson, H., Flagan, R. C., and Seinfeld, J. H.: Constraining the contribution of organic acids and $\mathrm{AMSm} / \mathrm{z} 44$ to the organic aerosol budget: On the importance of meteorology, aerosol hygroscopicity, and region, Geophys. Res. Lett., 37, L21807, https://doi.org/10.1029/2010gl044951, 2010. 
Sorooshian, A., Wang, Z., Coggon, M. M., Jonsson, H. H., and Ervens, B.: Observations of Sharp Oxalate Reductions in Stratocumulus Clouds at Variable Altitudes: Organic Acid and Metal Measurements During the 2011 EPEACE Campaign, Environ. Sci. Technol., 47, 7747-7756, https://doi.org/10.1021/es4012383, 2013.

Sullivan, R. C. and Prather, K. A.: Investigations of the diurnal cycle and mixing state of oxalic acid in individual particles in Asian aerosol outflow, Environ. Sci. Technol., 41, 8062-8069, 2007.

Sullivan, R. C., Guazzotti, S. A., Sodeman, D. A., and Prather, K. A.: Direct observations of the atmospheric processing of Asian mineral dust, Atmos. Chem. Phys., 7, 1213-1236, https://doi.org/10.5194/acp-7-1213-2007, 2007.

Wang, Z., Wang, T., Guo, J., Gao, R., Xue, L. K., Zhang, J. M., Zhou, Y., Zhou, X. H., Zhang, Q. Z., and Wang, W. X.: Formation of secondary organic carbon and cloud impact on carbonaceous aerosols at Mount Tai, North China, Atmos. Environ., 46, 516527, https://doi.org/10.1016/j.atmosenv.2011.08.019, 2012.

Wonaschuetz, A., Sorooshian, A., Ervens, B., Chuang, P. Y., Feingold, G., Murphy, S. M., de Gouw, J., Warneke, C., and Jonsson, H. H.: Aerosol and gas re-distribution by shallow cumulus clouds: An investigation using airborne measurements, J. Geophys. Res.-Atmos., 117, D17202, https://doi.org/10.1029/2012jd018089, 2012.

Yang, F., Chen, H., Wang, X. N., Yang, X., Du, J. F., and Chen, J. M.: Single particle mass spectrometry of oxalic acid in ambient aerosols in Shanghai: Mixing state and formation mechanism, Atmos. Environ., 43, 3876-3882, 2009.

Yang, F., Gu, Z. P., Feng, J. L., Liu, X. H., and Yao, $X$. H.: Biogenic and anthropogenic sources of oxalate in PM2.5 in a mega city, Shanghai, Atmos. Res., 138, 356-363, https://doi.org/10.1016/j.atmosres.2013.12.006, 2014.

Yu, J. Z., Huang, X. F., Xu, J. H., and Hu, M.: When aerosol sulfate goes up, so does oxalate: Implication for the formation mechanisms of oxalate, Environ. Sci. Technol., 39, 128-133, https://doi.org/10.1021/Es049559f, 2005.

Zauscher, M. D., Wang, Y., Moore, M. J. K., Gaston, C. J., and Prather, K. A.: Air Quality Impact and Physicochemical Aging of Biomass Burning Aerosols during the 2007 San Diego Wildfires, Environ. Sci. Technol., 47, 7633-7643, https://doi.org/10.1021/es4004137, 2013.
Zhang, G. H., Bi, X. H., Chan, L. Y., Li, L., Wang, X. M., Feng, J. L., Sheng, G. Y., Fu, J. M., Li, M., and Zhou, Z.: Enhanced trimethylamine-containing particles during fog events detected by single particle aerosol mass spectrometry in urban Guangzhou, China, Atmos. Environ., 55, 121-126, https://doi.org/10.1016/j.atmosenv.2012.03.038, 2012.

Zhang, Y. L., Kawamura, K., Fu, P. Q., Boreddy, S. K. R., Watanabe, T., Hatakeyama, S., Takami, A., and Wang, W.: Aircraft observations of water-soluble dicarboxylic acids in the aerosols over China, Atmos. Chem. Phys., 16, 6407-6419, https://doi.org/10.5194/acp-16-6407-2016, 2016.

Zhou, S., Collier, S., Jaffe, D. A., Briggs, N. L., Hee, J., Sedlacek Iii, A. J., Kleinman, L., Onasch, T. B., and Zhang, Q.: Regional influence of wildfires on aerosol chemistry in the western US and insights into atmospheric aging of biomass burning organic aerosol, Atmos. Chem. Phys., 17, 2477-2493, https://doi.org/10.5194/acp-17-2477-2017, 2017.

Zhou, Y., Wang, T., Gao, X. M., Xue, L. K., Wang, X. F., Wang, Z., Gao, J. A., Zhang, Q. Z., and Wang, W. X.: Continuous observations of water-soluble ions in PM2.5 at Mount Tai (1534 ma.s.1.) in central-eastern China, J. Atmos. Chem., 64, 107-127, https://doi.org/10.1007/s10874-010-9172-z, 2009.

Zhou, Y., Huang, X. H., Bian, Q., Griffith, S. M., Louie, P. K. K., and Yu, J. Z.: Sources and atmospheric processes impacting oxalate at a suburban coastal site in Hong Kong: Insights inferred from 1-year hourly measurements, J. Geophys. Res.Atmos., 120, 9772-9788, https://doi.org/10.1002/2015jd023531, 2015. 